\title{
On the sources of business cycles in the G-7 .
}

\author{
Fabio Canova * \\ Universitat Pompeu Fabra; University of Southampton; and CEPR \\ Gianni de Nicoló \\ Division of International Finance \\ Board of Governors of the Federal Reserve System \\ First Draft, October 1999 \\ This draft, March 2000
}

\begin{abstract}
This paper examines sources of cyclical movements in output, inflation and the term structure of interest rates. It employs a novel identification approach which uses the sign of the cross correlation function in response to shocks to catalog orthogonal disturbances. We find that demand shocks are the dominant source output, inflation and term structure fluctuations in six of the G-7 countries. Within the class of demand disturbances, nominal shocks are dominant, but their importance declined after 1982. Furthermore, there are no significant differences in the proportion of term structure variability explained by different structural sources at different horizons.
\end{abstract}

JEL Classification No.: C68, E32, F11.

Key words: Structural Shocks, Business Cycles, Demand Disturbances, Dynamic Correlations, Impulse Responses

\footnotetext{
*The views expressed are solely responsibilty of the authors and should not be interpreted as reflecting the views of the Board of Governors of the Federal Reserve System.
} 


\section{Introduction}

The term "business cycle" refers to the presence of common elements in the cyclical behavior of macroeconomic aggregates. Several authors, including Baxter and Stockman (1989), Blackburn and Ravn (1992), Backus and Kehoe (1992), Fiorito and Kollintzas (1994) and Gregory, Head and Raynauld (1997) among others, have documented the properties of cycles in economic activity in different countries using a variety of methods.

Whether cyclical movements in economic activity are primarily attributable to demand or supply disturbances is a question with a long standing tradition, tackled from many points of view but with often contradictory answers, see e.g. Blanchard (1989), King, Plosser, Stock and Watson (1991), Cooley and Ohanian (1991), Christiano and Eichenbaum (1992), Gali (1992) and (1999) among others. Open economy extensions, e.g. Amhed, et. al. (1993) or Canova and Marrinan (1998), have similarly reached opposite conclusions. Within this literature, the question concerning the real effects of monetary policy has received substantial attention in recent years (see e.g. Leeper, Sims and Zha (1996) or Christiano, Eichenbaum and Evans (1996)).

The interest in the sources of cyclical fluctuations stems from two different angles. First, researchers engaged in constructing models of the business cycle are interested in knowing whether a small number of disturbances is sufficient to capture the dynamics of the actual data, and in characterizing their typology. Second, policymakers care about what drives the cycle when making day to day decisions about the conduct of monetary and fiscal policy. If, as widely perceived, fluctuations are undesirable and demand shocks are largely responsible, there may be a role for aggregate Keynesian-type policies cushioning the economy. On the other hand, as often emphasized in the real business cycle literature, if cyclical fluctuations in economic activity are the optimal response to unforeseen disturbances, rather than mitigating fluctuations per se, a more appropriate role for the government is to reduce economically relevant uncertainties.

In this paper we attempt to assess what generates cyclical movements in economic activity using a novel two-step procedure. First, we extract orthogonal innovations from reduced form residuals using a statistical-based approach. These innovations have, in principle, no economic interpretation, but they have the property of being contemporaneously and serially uncorrelated. In the second step, we examine their informational content using standard aggregate macroeconomic theory, typically exemplified in an undergraduate textbook by a downward sloping aggregate demand curve, an upward sloping short run aggregate supply curve and a vertical long run aggregate supply curve in the output (gap)-inflation space. If, for example, a positive temporary orthogonal innovation in one variable is a supply disturbance, then it should generate positive transitory output responses, negative transitory responses in inflation and an upward movement in real balances. On the other hand, if a positive temporary orthogonal innovation is a real demand disturbance, e.g. increases in government purchases, then it should generate positive transitory responses in output and inflation and negative transitory responses in real balances. Finally, if a positive temporary orthogonal innovation is a nominal demand disturbance, e.g. due to an unexpected increase in the money supply, then it should generate positive responses of output, inflation and real balances. Hence, the comovements of these three variables in response to an orthogonal shock can be used to identify the informational content of orthogonal disturbances. 
Our identification approach has a number of advantages over competing ones. First, relative to Cooley and Ohanian (1991) or Chada and Prasad (1994)), who have used unconditional contemporaneous cross correlations of output and prices (or output and inflation), we use conditional cross-correlations in response to orthogonal shocks to establish sources of business cycles fluctuations. Unconditional correlations have been proved to be a fallacious instrument to recover structural shocks, unless additional restrictions are imposed on the DGP of the data (see Judd and Trehan (1995)). Second, relative to standard structural VAR analyses, e.g. Blanchard and Quah (1989), our procedure clearly separates the statistical problem of orthogonalizing the covariance matrix of reduced form shocks from issues concerning the identification of structural disturbances. More importantly, instead of imposing "sluggish" restrictions on impact responses, which maybe inconsistent with a large class of general equilibrium monetary models (see Canova and Piña (1999)), or on the long run response of certain variables to shocks, for which distortions due to measurement errors and small sample biases may be substantial (see e.g. Faust and Leeper (1997)), we employ theoretical restrictions on the sign and the shape of the dynamic responses of a vector of variables to examine whether orthogonal disturbances have any interesting economic interpretation.

As it is common in the literature, we do not attempt to identify all possible structural sources of fluctuations. We focus instead on the identification of a set of shocks, which we generically call supply and demand (real and nominal), whose dynamic effects can be characterized in the context of a large class of macroeconomic models. Once we have recovered the information content of orthogonal innovations, we quantify their importance in generating output and inflation cycles across countries. We also study how the identified sources of disturbance affect the variability of the slope of the term structure across countries. It is known that movements in the slope of the term structure have predictive power for future movements in real activity at short horizons and inflation at long horizons in many countries in the G-7 (see e.g. Plosser and Rowenshort (1994)). Our analysis attempts to give a structural interpretation to this phenomenon. One important aspect of our exercise, which distinguishes it from the existing literature, is the international focus of the comparison.

Three major conclusions can be drawn from our analysis. First, demand shocks are the most important source of output and inflation fluctuations in 6 of the G-7 countries. Within this class of shocks, nominal shocks are dominant. Second, identified demand shocks account for significant variations in the slope of the term structure, but we do not find significant differences in the proportion of term structure variability explained by different structural sources at different horizons. Third, although in the latter part of the sample output and inflation cycles are practically synchronized in the G-7 countries, there are still significant heterogeneities in both the sources of cycles and in the contribution of different types of shocks to output and inflation variability.

Our qualitative results are broadly robust to sample splitting with one qualification. The informational content of orthogonal VAR innovations and their predictive power for the variability of output and inflation change somewhat across subsamples. Results are also robust to the use of alternative estimation techniques.

The finding that demand shocks play a dominant role in generating real, nominal and financial fluctuations in G-7 countries casts some doubts on theoretical efforts explaining business fluctuations via technological disturbances, and suggests that a careful monitoring of demand 
conditions may still be an important objective of government policies. Furthermore, the fact that nominal disturbances are important provides empirical support for the recent resurgence of interest in theoretical models where nominal shocks are the engine of business cycles.

The reminder of the paper is organized as follows. Next section presents the reduced form model and the issues connected with its specification. Section 3 discusses the basic intuition behind our identification procedure and presents a version of a general equilibrium shoppingtime model which provides a way to interpret conditional cross-correlations for the variables of interest. Section 4 presents the results of our investigation. Section 5 analyzes how the slope of the term structure reacts to identified structural shocks. Section 6 concludes.

\section{The specification of the model}

Our reduced form model is an unrestricted VAR. We use two alternative setups: single country VAR models including a measure of real activity (IP), of inflation (INF), of the slope of the term structure of the nominal interest rates (TERM) and of real balances (M/P); and a pooled VAR with country specific fixed-effect containing the same four variables for all countries. The sample we use covers monthly data from 1973:1 to 1995:7; industrial production, CPI and nominal interest rates are from the OECD database while monetary (M1) data are from IFS statistics. All series are seasonally adjusted.

Reduced form VAR models, which include real activity, inflation and a measure of interest rates and money have been examined by many authors in the literature (e.g. Sims (1980); Farmer (1997)). Here we maintain the same structure except that we employ a measure of the slope of the term structure in place of a short term interest rate. We do this because recent results by Stock and Watson (1989), Estrella and Hardouvelis (1991), Plosser and Rowenshort (1994) demonstrated the superior predictive power of the slope of term structure for real activity and inflation relative to a single measure of short term interest rates in the US and in some European countries. Also, the slope of the term structure has information about nominal impulses that other variables, such as unemployment or real wages, may not have. We also differ from part of the literature in the fact that we use real balances, as opposed to nominal ones. One justification for this choice is that the model we present in the next section has important implication for real balances. Another is that the responses of real balances allow us to distinguish nominal from real demand disturbances. We have experimented with specifications including other variables (e.g. stock returns) or with using both a short and a long term nominal rate separately. The results we present are insensitive to these changes.

In order to interpret responses to shocks as short term dynamics around a stationary (steady) state, the VAR must be stationary, possibly around a deterministic trend. Given the relative small size of our data set, tests for integration and cointegration are likely to have low power and this may affect economic inference at a second stage. We therefore prefer to be guided by economic theory in selecting relevant variables and use a subset which is likely to be stationary under standard assumptions. The model we present in section 3 generates stationary paths for linearly detrended output, inflation, term structure and real balances. The time series plots for the four variables in the seven countries after linearly detrending show no evidence of non-stationarities. For the corresponding VAR models, the Schwarz criteria indicate that the 
dynamics for all countries are well described by a VAR(1), except for Japan, where we use a $\operatorname{VAR}(2)$.

Because the VAR is a reduced form model, the contribution of different sources of structural disturbances to output and inflation cycles cannot be directly computed. To obtain structural shocks we proceed in two steps. First, we construct innovations from reduced form residuals having the property of being serially and contemporaneously uncorrelated. Second, we use theory to tell us whether any of the components of the orthogonal innovation vector has a meaningful economic interpretation. If the orthogonal shocks we have built do not have a structural interpretation, we construct alternative orthogonal innovations and repeat the exercise.

Formally, let the VAR representation of the system be:

$$
Y_{t}=\mu+A(\ell) Y_{t-1}+u_{t} \quad u_{t} \sim(0, \Sigma)
$$

where $Y_{t}$ is a $4 \times 1$ vector and $A(\ell)$ a matrix polynomial in the lag operator. Then, for any nonsingular orthogonal matrix $V$ satisfying $\Sigma=V V^{\prime}$, (1) can be transformed to have contemporaneously uncorrelated innovations. A general orthogonalization which achieves the purpose is an eigenvalue-eigenvector decomposition of the form $\Sigma=P D P^{\prime}=V V^{\prime}$ where $P$ is a matrix of eigenvectors, $D$ is a diagonal matrix with eigenvalues on the main diagonal and $V=P D^{\frac{1}{2}}$. Given this decomposition, (1) can be transformed into:

$$
\tilde{Y}_{t} \equiv V^{-1} Y_{t}=\tilde{\mu}+A(\ell) \tilde{Y}_{t-1}+\tilde{u}_{t}
$$

where $\tilde{\boldsymbol{e}}_{t}=V^{-1} u_{t} \sim(0, I), \tilde{\mu}=V^{-1} \mu$. Let the moving average representation be:

$$
\tilde{Y}_{t}=\phi+C(\ell) \tilde{e}_{t}
$$

where $\phi=(I-A(\ell) \ell)^{-1} \tilde{\mu}$ and $C(\ell) \equiv\left\{c^{i j}(\ell)\right\}=(I-A(\ell) \ell)^{-1}$.

As shown in the next section, economic theory provides important information on the pairwise dynamic cross correlations in response to shocks. Using (3) the pairwise dynamic cross correlations conditional on a shock can be calculated as

$$
\rho_{i j \mid k}(r) \equiv \operatorname{Corr}\left(\tilde{Y}_{i t}, \tilde{Y}_{j, t+r} \mid \tilde{e}_{k t}=1\right)=\frac{\left(\sum_{s=0}^{\infty} c_{s}^{i k} \sum_{s=0}^{\infty} c_{r+s}^{j k}\right)}{\sqrt{\left(\sum_{s=0}^{\infty} c_{s}^{i k}\right)^{2}\left(\sum_{s=0}^{\infty} c_{r+s}^{j k}\right)^{2}}}
$$

where $k$ indicates the shock, $i, j$ the variables under consideration, $r$ the horizon of the responses. Our task is to examine whether for some $k$ and for certain variables $i, j, \rho_{i j \mid k}(r)$ conforms with the predictions of economic theory for different values of $r$. If $\rho_{i j \mid k}(r)$ is not interpretable for some $k$, notice that for any orthogonal $Q$ such that $Q Q^{\prime}=I, \Sigma=\hat{V} \hat{V}^{\prime}=V Q Q^{\prime} V$ is an admissible decomposition of the covariance matrix of the VAR residuals. Hence, we can repeat the exercise and examine if orthogonal shocks have a theoretical interpretation under the $\hat{V}$ decomposition.

A class of orthogonal matrices like $Q$ useful for our purposes are rotation matrices. These 
matrices have a simple representation in terms of sine, cosine functions and ones of the form:

$$
Q_{m, n}=\left(\begin{array}{cccccc}
1 & 0 & 0 & \ldots & 0 & 0 \\
0 & 1 & 0 & \ldots & 0 & 0 \\
\ldots & \ldots & \ldots & \ldots & \ldots & \ldots \\
0 & 0 & \cos (\theta) & \ldots & -\sin (\theta) & 0 \\
\vdots & \vdots & \vdots & 1 & \vdots & \vdots \\
0 & 0 & \sin (\theta) & \ldots & \cos (\theta) & 0 \\
\ldots & \ldots & \ldots & \ldots & \ldots & \ldots \\
0 & 0 & 0 & 0 & 0 & 1
\end{array}\right)
$$

where the subscript $(m, n)$ indicates that only rows $m$ and $n$ are rotated by the angle $\theta$. Press at al. (1980) show $P=\prod_{m, n} Q_{m, n}$ so that the original eingevector matrix is the product of successive rotation matrices.

Since in a system of $\mathrm{N}$ variables there are $(\mathrm{N}(\mathrm{N}-1) / 2)$ bivariate rotations and $(\mathrm{N}(\mathrm{N}-1) / 4)$ combinations of bivariate rotations of different elements of the VAR, there are 9 possible rotations one can undertake for every angle $\theta$ in our system. Although $\theta$ is periodic $\bmod (2 \pi)$, there is an infinite number of possible values of $\theta \in(0,2 \pi)$ that could be selected. This multiplicity poses two important problems. First, how to conduct the search systematically over the space of $\theta$ for each rotation. Second, how to proceed when different orthogonal representations of VAR residuals recover one or more interpretable disturbances.

Our algorithm works in three steps. First, we divide the space $[0,2 \pi]$ with a relatively fine grid therefore reducing an infinite dimensional problem to a finite dimensional one. Second, for each grid point we use the sign of $\rho_{i j \mid k}(r=0)$ to identify shocks. Among all the decompositions we calculate, we concentrate on those that maximize the number of shocks exhibiting conditional correlations consistent with theory. If there is no decomposition for which all four shocks are identifiable, we restrict the attention to those for which only three shocks are identifiable, and so on. Third, if there is more than one decomposition that produces the same number of identifiable shocks, we sequentially eliminate "wrong" ones using the sign of the conditional cross correlation function for $r \neq 0$. This amounts to eliminating orthogonal decompositions which produce unreasonable shapes in the impulse responses.

In our case these three steps were sufficient to select a unique orthogonalization for each country. If this were not the case, one could eliminate remaining ties using the magnitude of the elements of $\rho_{i j \mid k}(r)$ for different $r$ (if theory provides this information), or by making the identification requirements more stringent, e.g. adding the pairwise correlation between the variables of the system and an additional one and requiring that the signs at $r=0$ and/or $r \neq 0$ match those implied by theory.

Once we have determined the informational content of the orthogonal innovations, we measure their contribution to output and inflation cycles using the variance decomposition. The variance of $Y_{i t}$ allocated to sources in $\tilde{e}_{k t}$ at horizon $\tau$ is

$$
z^{\tau}(i, k)=\frac{\sum_{s=0}^{\tau-1}\left(c_{s}^{i k}\right)^{2}}{\sum_{k=1}^{4} \sum_{s=0}^{\tau-1}\left(c_{s}^{i k}\right)^{2}}
$$

where $\sum_{k=1}^{4} z^{\tau}(i, k)=1$. We compute confidence bands for the $z^{\tau}(i, k)$ numerically, drawing 
1000 Monte Carlo replications, ordering them and extracting the $68 \%$ band (from the 16 th to the 84 th percentile).

It is worth commenting on the differences between our identification approach and the one commonly used in structural VARs (SVAR). In SVAR one imposes "economic" or "sluggish" restrictions on the matrix of impact coefficients or on long run multipliers and interprets the resulting long run (short run) dynamics. The imposition of economically or informationally motivated restrictions achieves two goals at once: disentangle the reduced form shocks and make them structurally interpretable.

The two step approach we propose separates the statistical problem of producing uncorrelated VAR shocks from the economic one of interpreting them. Also, instead of imposing zero restrictions on the contemporaneous impact of shocks, restrictions which may be inconsistent with a large class of general equilibrium models (see Canova and Piña (1998)), or on their long run impact for which small sample biases may be substantial (see Faust and Leeper (1997)), we use the sign and the shape of comovements of a vector of variables in response to shocks to identify their informational content.

Our approach has some similarities with those of Uhlig (1999) and Faust (1998). The main difference between our approach and theirs is that our method is more informal. However, contrary to theirs, it allows to systematically evaluate the informational content of shocks for a large set of orthogonal decompositions and to sequentially impose more stringent restrictions to eliminate uninteresting decompositions with a method-of-moment-type procedure.

Finally, while Cooley and Ohanian (1991), Chada and Prasad (1994) have considered simple unconditional cross correlation function, we consider the cross correlation function conditional on the shocks to identify sources of cyclical variation. Judd and Trehan (1995) have forcefully argued that simple cross correlations may be unable to discern sources of cyclical fluctuations unless further assumptions are made on the dynamics of the variables in question. Conditional cross correlations do not face these problems and provide an effective and alternative way to approach the identification problem.

\section{Theory}

The idea behind our approach to identify the informational content of orthogonal innovations is very simple. Consider a standard undergraduate textbook picture (see e.g. Bernanke and Abel (1995), p. 382) depicting a downward sloping aggregate demand curve (AD), an upward sloping short-run aggregate supply curve (SRAS) and a vertical long-run aggregate supply curve (LRAS) in the inflation-output plane.

Suppose we observe a temporary negative inflation innovation. If it is driven by a temporary (positive) supply disturbance it should generate a positive response of output in the short run, increase money demand and produce a positive response in real balances. These changes in the equilibrium values of the variables are caused by an outward movement of the SRAS curve, keeping AD and LRAS fixed. Suppose, on the other hand, that a positive inflation innovation is driven by a temporary (positive) real demand disturbance, for example, an increase in government expenditure financed by bond creation. In that case we should observe a positive short-run response in output and a decline in real balances. These changes are the result of an outward 
movement in AD curve, keeping SRAS and LRAS fixed. Finally, suppose a positive inflation innovation is driven by a temporary shock in money growth. Then, we should also observe a positive response of output, if money has real effects and a positive response of real balances, if prices do not fully adjust instantaneously. This combined set of circumstances is obtained by moving the AD curve along the SRAS curve, keeping the LRAS curve fixed.

A similar pattern must hold when we observe a temporary innovation in output. If it is driven by a (positive) supply disturbance, it should be associated with temporary decrease inflation and an increase in real balances. On the other hand, if it is generated by a positive temporary real (nominal) demand disturbance, it should be associated with a positive transitory increase in inflation while real balances should decline (increase).

Therefore, these three types of disturbances produce joint comovements of output, inflation and real balances of different signs. The undergraduate textbook approach has not much to say about the exact timing of these comovements. If prices are flexible, the majority of the adjustments should occur almost contemporaneously. Hence the pairwise contemporaneous cross-correlation of these three variables in response to innovations can be used to identify the informational content of shocks. If prices are sticky, peak responses may occur with a delay. Furthermore, if there is sluggishness in output adjustments, nominal shocks may take time to propagate to the system. In all these cases the leads and lags of the pairwise cross correlation function contain the information needed to identify structural disturbances.

The response of the term structure of nominal interest rates to the three structural shocks depends on the exact features of the underlying economy. For example, when capital is fixed over the adjustment path, supply and (real) demand disturbances may increase or decrease shortterm interest rates relative to long-term ones, depending on the elasticity of the money demand function and on how impatient agents are in their consumption needs. This lack of robustness is further complicated in the case of nominal disturbances by the presence of liquidity and the expected inflation effects. When the former dominates (due to a temporary decrease in the real rate combined with a temporary increase in inflation of smaller size), the slope of the nominal term structure will temporarily increase in response to expansionary monetary policy shocks. If the latter prevails, the slope of the nominal term structure will decline. Since the responses of the slope of the term structure to structural shocks depends on the features of the economy, we will not use them to provide additional information overidentifying shocks.

Since the suggested identification scheme is based on static economic theory, it is legitimate to wonder whether shocks in models with micro-foundations generate similar dynamic responses. The class of models whose reduced form innovations move aggregate demand and supply curves in the way we have described is relatively broad. For example, in Lucas (1972) model, where agents cannot distinguish shocks to relative prices from shocks to the aggregate price level, demand and supply disturbances produce comovements in output, inflation and real balances with the required characteristics. New-keynesian models with menu costs and/or sticky-price monopolistic competition of the type examined by Mankiw (1985) or Gali (1999), are able to generate the pattern of comovements in response to demand and supply disturbances we have outlined, even though the quantitative features of inflation and output responses in the short run will be different from those produced by Lucas' model. Similarly, models of indeterminacy of the type described in Farmer (1997) produce outcomes, which are qualitatively similar to new-keynesian ones. Finally, market clearing general equilibrium RBC models are also able to 
generate a reduced form that fits the prototype model of AS-AD curves and generate the joint dynamics in response to innovations we have described.

To outline one such a model consider the following shopping-time economy, very similar to the one in Den Haan (1990). There is a representative agent which needs either time or money to purchase consumption goods and sells labor to a representative firm. Following the existing literature we abstract from capital. At the beginning of each $t$ shocks to technology, government purchases and money growth are realized, money is distributed to agents who exchange money for bonds in financial markets according to their needs. When financial markets close agents sell labor on competitive labor markets. Afterwards production takes place, the government takes a fraction of output away for its own purposes and what is left is sold to consumers which pay cash for their purchases. Since firms are owned by consumers, the proceedings of the sale are distributed to the household in the form of wages and profits, the firm shutdowns at the end of period $t$ to reopen at $t+1$ under the same arrangement. The problem for the representative consumer/firm is:

$$
\max _{\left\{c_{t}, l_{t}, M_{t}, B_{t}\right\}} E_{0} \sum_{t=0}^{\infty} U\left(c_{t}, l_{t}\right)
$$

subject to:

$$
\begin{aligned}
l_{t} & =1-h_{t}-v_{t} \\
c_{t}+\frac{B_{t+1}}{p_{t}}+\frac{M_{t+1}}{p_{t}} & =\left(y_{t}-g_{t}-T_{t}\right)+\frac{M_{t}}{p_{t}}+\frac{B_{t}}{p_{t}}\left(1+I_{t}\right)
\end{aligned}
$$

where $y_{t}=f\left(h_{t}, A_{t}\right)$. The government budget constraint and the supply of money are given by

$$
\begin{aligned}
\frac{M_{t+1}-M_{t}}{p_{t}} & =T_{t}+\frac{B_{t+1}}{p_{t}}-\frac{B_{t}}{p_{t}}\left(1+I_{t}\right) \\
M_{t+1}^{s} & =\left(1+\mu_{t+1}\right) M_{t}^{s}
\end{aligned}
$$

where $\mu_{t}$ is the growth rate of the money supply, $A_{t}$ is a technology disturbance, $g_{t}$ are government purchases of goods, $T_{t}$ are lump sum transfers of money, $B_{t}=\bar{B}$ is the stock of outstanding bonds, and $I_{t}$ the one period interest rate, $v_{t}$ is shopping time, $l_{t}$ is leisure, $h_{t}$ hours worked and $p_{t}$ is the price level at $t$. We also assume that all uncertainty about the state of the economy is realized before agents take any decision concerning labor supply, money demand and consumption purchases.

Define $m_{t}=\frac{M_{t}}{p_{t}}$, and $b_{t}=\frac{B_{t}}{p_{t}}=\frac{\bar{B}}{p_{t}}$. We assume that the utility function is of the form $U\left(c_{t}, l_{t}\right)=\frac{\left(c_{t}^{\delta} l_{t}^{1-\delta}\right)^{\tau}-1}{\tau}$, that the shopping time technology is $v_{t}=v\left(c_{t}, m_{t}\right)=c_{t}\left(\frac{M_{t}}{p_{t} c_{t}}\right)^{\gamma}+\eta_{2} \frac{M_{t}}{p_{t}}$ where $\gamma=-\frac{\eta_{1}}{1-\eta_{1}}$, and the production function is $f\left(h_{t}, A_{t}\right)=h_{t}^{\alpha} A_{t}$. The three first order conditions of the problem, the shopping time constraint ( 7$)$, the resource constraint, the production function, the money supply rule (10), the budget constraint of the monetary authority (9) and an Euler equation for nominal bonds of the form

$$
\frac{1+\pi_{t+k}}{1+I_{t+k}}=\beta \frac{\lambda_{t+k}}{\lambda_{t}}
$$

$k=1,2, \ldots$ where $\pi_{t+k}$ is the $\mathrm{k}$-period inflation rate at $t, I_{t+k}$ is the k-period nominal interest rate at $t$ and $\lambda_{t}$ is the lagrange multiplier on the budget constraint (8), constitute a nonlinear 
system of 9 equations in 9 unknowns $\left(m_{t+1}, \pi_{t+1}, I_{t+1}, c_{t}, h_{t}, l_{t}, v_{t}, y_{t}, T_{t}\right)$ with three driving processes $\left(A_{t}, g_{t}, \mu_{t}\right)$. It is easy to show that, once the above conditions are log-linearized around the steady state, such a system can be collapsed into a trivariate system of first order difference equations for $W_{t+1}=\left(\hat{m}_{t+1}, \hat{\pi}_{t+1}, \hat{I}_{t+1}\right)$ of the form

$$
A_{1} W_{t+1}=A_{2} W_{t}+D_{1} E_{t+1}+D_{2} E_{t}
$$

where $E_{t}=\left[\hat{A}_{t}, \hat{g}_{t}, \hat{\mu}_{t}\right]$ and hats indicate percentage deviations from the steady state. We assume $E_{t}=\bar{E}+\rho E_{t-1}+u_{t}, \quad u_{t} \sim(0, \Sigma)$ and construct the slope of the term structure by taking the difference between a long term rate and a short one $\left(S L_{t}=\lim _{k \rightarrow \infty} \hat{I}_{t+k}-\hat{I}_{t+1}\right)$.

In figure 1 we report the theoretical pairwise cross correlation function of output, inflation real balances, conditional on each of the three disturbances when $\rho=\operatorname{diag}[0.99,0.90,0.50] * I, \delta=$ $0.8, \tau=5, \alpha=0.64, \eta_{1}=2.5, \eta_{2}=1.0, \beta=0.99$. With these choices the steady state values of leisure, consumption to real balances, consumption to output, and money growth, are respectively, $\bar{l}=0.7, c / m=1 / 6, c / y=0.7, \bar{\mu}=0.006$. Note that the values for $\eta_{1}, \eta_{2}$ and for the steady state are very close to those of Gavin and Kydland (1999).

In this model, a technology disturbance generates negative contemporaneous cross correlations between output and inflation. The cross correlation between inflation and real balances and between real balances and output is S-shaped with different inflexion points. However, contemporaneously the former is negative and the latter is positive. Government expenditure shocks produce a positive contemporaneous cross correlation between output and inflation. The cross correlation between inflation and real balances has an S-shape and the one between real balances and output has an inverted S-shape. In both cases, the contemporaneous cross correlation is negative. Finally, monetary disturbances produce positive cross correlations for all pairs of variables.

The interpretation of the dynamics generated by the three shocks is very simple. Given a process for $M_{t}$, a surprise increase in $\hat{A}_{t}$ increases output and consumption on impact since $g_{t}$ is constant at its steady state level. This increase in consumption requires an increase in the money needed to finance expenditure. With a fixed money supply, short term nominal rates increase (the slope of the term structure declines) to make agents hold exactly the right amount of money. Shopping time also increases and this requires that either leisure or hours decline to keep the time constraint satisfied. Because the wealth effect of the shock is strong, hours decline and leisure increases temporarily. Note that because labor demand by firms has increased the real wage is higher after the shocks, making the wealth effect even stronger. In other words, as agents become more productive, they devote more time to shopping and to leisure and less to production. Also, because the nominal rate increases and the inflation rate declines, real balances and the ex-post real rate increases substantially after the shock.

A unitary surprise increase in $\hat{g}_{t}$ makes $c_{t}$ decline and, because of a wealth effect, labor supply and output increase. Given the money supply, aggregate demand increases and this raises prices on impact. Since consumption declines, money demand also declines and the short term rate decreases (the slope of term structure increases) to induce agents to hold exactly the amount of money in circulation. As a consequence, shopping time and leisure decline to maintain the time constraint satisfied and real balances and ex-post real returns also decline.

Finally, a unitary surprise increase in $\mu_{t}$ decreases the shopping time needed to finance consumption and this frees time resources for alternative activities. Hence both leisure and 
hours increase, leading to an increase in output and consumption. Furthermore, as money increases are larger than output increases there will be inflation. However, since the increase in inflation is smaller than the increase in $\mu_{t}$, real balances increase. With the parameterization we used, the expected inflation effect dominates the liquidity effect of a monetary shock so that nominal short term rates increase on impact ${ }^{1}$.

In conclusion, the model generates the same sign restrictions on the cross correlation function in response to structural disturbances as the standard textbook approach. Since the joint dynamic behavior of output, inflation and real balances in response to shocks is shared by a large class of models with different micro-foundations, we feel confident in using sign restrictions to disentangle structural disturbances without reference to any specific model.

\section{The results}

\subsection{Identifying the disturbances: The US}

To illustrate how the identification procedure works we first examine sources of fluctuations in US output and inflation in detail. Figures 2 and 3 present, respectively, the estimated cross correlation function for inflation and industrial production, inflation and real balances, real balances and industrial production, conditional on the four orthogonalized VAR innovations for $r=-4, \ldots, 0,1, \ldots, 4$; the impulse response of the variables of the system to each orthogonal innovations. All figures are constructed orthogonalizing the covariance matrix of the shocks with an eigenvalue-eigenvector decomposition and rows 1 and 3 and rows 2 and 4 of the standardized eigenvector matrix simultaneously rotated by the angle $\theta=0.94$. We have selected this decomposition because it allows us to identify all shocks using the contemporaneous cross correlation function, and because, among the two orthogonalizations which produce this outcome, the impulse responses it produces are interpretable.

Figure 2 shows that the first and fourth orthogonal shocks produce positive pairwise contemporaneous cross correlations functions in the relevant range, and therefore qualify as nominal disturbances. The second orthogonal shock produces cross correlation functions for inflation and output and inflation and real balances with negative contemporaneous values, and a positive contemporaneous cross correlation function for real balances and output. Hence, this shock looks like a supply disturbance. The third orthogonal shock produces a positive cross correlation function between industrial production and inflation and negative cross correlation functions for the other two pairs of variables. Thus, it appears to be a real demand disturbance.

Figure 3 shows that the two nominal disturbances produce very different dynamics in the system. The first shock has sizable effects on industrial production, increases inflation while the short term rate temporarily decreases. Also, the response of real balances and industrial production is synchronized, suggesting that a cash-in-advance mechanism with constant velocity may be at work. The second nominal disturbance has smaller short run real effects. However, the impact response on inflation is sizable and the slope of the term structure declines considerably

\footnotetext{
${ }^{1}$ If we had set $\eta_{1}=2.0, \eta_{2}=-0.5$ the liquidity effect dominates generating lower interest rates, higher employment and output. However, with this parameterization the steady state consumption is too low to be consistent with the data and the cross-correlation function of output and inflation is negative in the relevant range.
} 
for about two years after the shock. The second orthogonal shock looks like a Lucas' (1972) supply disturbance: it produces a small increase in industrial production accompanied by a decline in inflation on impact, but this tendency is quickly reversed with inflation increasing and output declining for about two years. Real balances also increase in response to this disturbance, and long term rates decrease relative to short term ones. The third orthogonal shock induces adjustments typically associated with a real demand shock: if contractionary, a disturbance of this type causes both industrial production and inflation to decline on impact, real balances to increase and the short term rate to fall relative to the long term one.

The volatility of first nominal shock (shock 1) is constant over the entire sample. However, there are large spikes around 1987-1989 and significant negative movements in 1974, 1979 and around the so-called Romer and Romer dates. The other nominal shock (shock 4) displays high volatility in 1973-75 and 1979-82. After 1982 its volatility declines, and there are only two episodes of significant negative disturbances: in correspondence with the Plaza Agreement (end of 1985 ) and at the end of 1988 .

The supply shock (shock 2) has most of its fluctuations concentrated between 1979 and 1982, at a time when the real rate of interest was very volatile. Hence, although one maybe tempted to attribute this volatility to the choice of monetary targets by the Federal Reserve, our procedure selects such a shock as a supply disturbance, since it increases long term real rates (relative to short ones) and this contracts economic activity and inflation. The real demand shock (shock 3 ) has two large spikes, one around 1975 (positive) and one at the end of 1988 (negative), both of which seemed to be associated with substantial changes in consumer and government spending. Note also that this shock displays an increase in volatility between 1979 and 1982 and a stronger pattern of persistence in the 1990's.

In conclusion, when applied to US data, our identification approach recovers four disturbances whose historical path is reasonable and which produce interpretable dynamics.

\subsection{Identifying structural disturbances: The other G-7 countries}

We summarize the informational content of structural shocks in each country in table 1, where we also report the rotation employed and the angle of rotation used to achieve identification.

The table displays four important features. First, for the UK, France, Italy and Canada we identify the informational content of all four orthogonal shocks, while for Germany and Japan we are able to structurally interpret only three of the four shocks. Second, we identify at least one nominal disturbance in all six countries and in Japan, Italy and the UK three shocks appear to be of this type. Third, one of the orthogonal shocks in Germany and the UK is a real demand disturbance while in France there are two disturbances of this type. Finally, supply shocks are identifiable in France, Italy and Canada. In Canada three of the four identified shocks are of supply type.

We find three broad patterns of nominal disturbances across countries (Figure 4). At least one nominal shock in Germany, France, Italy, Japan and Canada fits our a-priori idea of what a policy disturbance should do, i.e. a shock which contracts nominal balances must decrease output, either on impact or with a short lag, reduce inflation instantaneously and make real balances decline while the short nominal interest rate must increase relative to long term ones.

One of the nominal shocks in Germany, UK and Japan has a perverse effect on output: if it 
increases the level of nominal balances, it produces a strong and persistent response of inflation and this makes real balances decline. Output then declines because demand falls. Changes in inflation expectations increase long term interest rates relative to short term ones. Given the size of inflation responses, we conjecture that this type of disturbances occur very close to full employment.

A final pattern of identified nominal shocks across countries appear to be linked to international factors. That is, their variability tends to increase at the time of turbulence in international money and financial markets and, in European countries, at the time of realignment of their exchange rates within the EMU. Positive realizations of this type of disturbances generate strong expected inflation effects and produce humped shaped responses in the term structure.

For real demand shocks there are no clear similarities across countries (Figure 5). They produce responses in output, inflation and real balances which have different magnitudes across countries, and responses in the slope of the term structure which often have different signs and shapes. On the other hand, supply shocks, if expansionary, produce a large increase in nominal short term rates relative to long term ones, a significant decrease in the slope of the real term structure and high ex-post real rates (Figure 6). Furthermore, there are interesting similarities in the time path of supply disturbances for the U.S. and Canada.

In sum, our procedure identifies nominal disturbances in all countries while it recovers real demand and supply disturbances only in four countries. The nominal disturbances we have identified have similar characteristics across countries, broadly associated with domestic expansionary effects, domestic expected inflation effects and international expected inflation effects. No common pattern is detectable in the time path and in the transmission of real demand shocks, while there is some evidence that identified supply disturbances in the US and Canada have a common component.

\subsection{The Explanatory Power of Structural Disturbances}

Having identified the informational content of orthogonal VAR innovations, we next calculate the contribution of structural shocks to output and inflation cycles for every country. What we compute in Germany and Japan are lower bounds because there are orthogonal innovations without a clear informational content. These innovations may also contain components of supply and demand disturbances, distinct from and uncorrelated with the ones we disentangle, so that the percentages we present could be augmented if, by means of other variables or additional information, we could uncover what drives the remaining "unnamed" innovations. Table 2 presents $68 \%$ bands for the forecast error variance decomposition of output and inflation at 24 steps due to structural disturbances. Varying the forecasting horizon between 12 and 48 steps has no effects on the results, since shocks are completely absorbed after 12 periods.

There are four important regularities in the table. First, in five of the seven countries demand shocks are the major source of fluctuations in industrial production. Only in Italy and Canada supply disturbances dominate, explaining $55-75 \%$ and $40-60 \%$ of the variability of industrial production, respectively. Second, among demand-type shocks, nominal disturbances are the most important source of variability in industrial production in the UK, in Germany and in Japan explaining, respectively, $37-77 \%, 95-99 \%$, and $22-45 \%$ of the variance of industrial production. Real demand disturbances dominate real fluctuations in US, and France explaining, respectively, 
29-76\% and $55-79 \%$ of the variance of industrial production. Third, demand disturbances are also the dominant source of inflation fluctuations in six of the seven countries and in four nominal disturbances play a dominant role (they explain between 54 and $98 \%$ of inflation variance). Supply disturbances constitute a significant source of inflation fluctuations in the US, Canada and Italy, while real demand disturbances are important in Germany and France and the US. Fourth, the three identified disturbances explain a large portion of the variability of output and inflation cycles in Germany. However, in Japan residual unexplained output variability remains.

\subsection{Sub-sample analysis}

The presence of subsample instabilities may distort our conclusions concerning the informational content of orthogonal VAR innovations and the importance of various structural disturbances as sources of output and inflation cycles. The domestic and international portions of monetary markets of all the G-7 countries have undertaken substantial changes over the sample. For example, capital controls and restrictions on domestic holdings of foreign currencies have been gradually eliminated during the 1980 's. Domestic banking constraints, e.g. regulation $\mathrm{Q}$ in the US or quotas on the portfolio of banks in several European countries, have also been scrapped over the sample period in favor of more market oriented policies. These changes may have substantially affected the way disturbances are transmitted to the real economy, as well as the adjustment lag needed for prices and quantities to adjust to the shocks.

In this subsection we present evidence obtained from two subsamples (73:1-82:10 and 82:1195:7) in order to check whether results are affected by subsample instabilities. It should be kept in mind that by breaking the sample we avoid to mix periods with different structural characteristics, but estimates of the cross-correlation functions are more likely to be imprecise, and the informational content of orthogonal VAR innovations more difficult to detect in the subsamples. We chose 1982:10 as common break point following the existing literature (see e.g. Kim (1999)): the first subsample includes the oil shocks, the inflationary period of the 1970's and the Volker experiment of targeting monetary aggregates, while the second sample covers the most recent years with declining inflation, increased economic integration and vigorous US expansion. For European countries there are historical episodes which may require further subdivisions (the German unification in 1990, the breakdown of the monetary snake in 1979 and of the EMS in 1992, and so on). We do not investigate how these additional breaks affect our conclusions, since the sample size becomes too short to provide reliable estimates of the cross correlation function. The time path of the identified disturbances in the two subsamples suggests that these episodes are better characterized as outliers than as structural breaks with changing dynamics.

For the first subsample the informational content of orthogonal innovations is similar to that of the full sample, but the number of identified shocks changes and the type of structural disturbances we disentangle is different. For example, we identify all four shocks in the US, Italy and Japan while we identify three shocks in the UK, France and Canada and only two shocks in Germany. Also, while in the full sample supply shocks were present in four countries, for the 1973-82 sample they appear to be active only in Italy. Furthermore, there is at least one source of real demand disturbances in all countries except Italy, while this was not the case in the full sample. 
Notice also that because of small sample problems, there are some countries (the UK and Canada) where there is still a large component of inflation variability which is not explained by identified shocks. Despite these differences, the general conclusions we have drawn for the full sample hold true also in this case. Demand disturbances are the only source of industrial production volatility in six of the seven countries and nominal disturbances significantly contribute the variability of industrial production in all countries but Germany. Similarly, demand disturbances dominate inflation variability in all seven countries.

In the second subsample, the results are slightly different. It is still true that demand disturbances dominate the variability of industrial production in six of the seven countries. However, the relative contribution of different types of shocks changes. For example, in Japan, the UK and France, the contribution of nominal disturbances for real fluctuations is modest, while they become more important in the US and Italy. Our procedure also identifies real demand disturbances in all countries but Germany and Italy. These shocks play a more important role relative to the full sample in explaining industrial production fluctuations in the UK, France and in Japan.

Supply shocks are identifiable in four countries, and in Italy and Canada there are three and two shocks of this type respectively. However, apart from Italy and France, these shocks account for negligible portions of industrial production variability.

A similar pattern holds for inflation variance: demand disturbances dominate the variability of inflation in five of the seven countries. The importance of nominal disturbances declines in US, Canada, Japan and Italy while it increases in Germany and the UK and real demand disturbances account for most of inflation variability in US and Germany. Supply disturbances explain a significant portion of inflation variability in France, Canada and Italy and dominate in these two latter countries.

In conclusion, the analysis of this subsection has highlighted three important facts. First, structural sources of disturbances driving output and inflation cycles appear to be changing over time. Nevertheless, demand disturbances are the most important source of industrial production variability in several countries in both subsamples. Second, the relative importance of the two demand disturbances for industrial production cycles is significantly altered across subsamples. Third, the events occurring in the first part of the sample tend to dominate the dynamics present in the full sample.

\subsection{Results from the Pooled Specification}

Instead of asking what are the sources of structural disturbances driving output and inflation cycles in each of the G-7 countries, one may be interested in knowing what is the "typical" information content of orthogonal VAR innovations in an average country of the panel. To investigate this question we examine a pooled VAR model with a country specific intercept where the dynamics in response to various structural disturbances are estimated using data from all countries. Such a model provides us with a cross sectional mean estimate of the pairwise cross correlation functions of the three variables of interest.

A pooled model correctly recovers the average informational content of orthogonal innovations if the DGP of the actual data were the same for all countries, apart from a level effect. When this is the case and the time series dimension of each sample is short, we can obtain 
more precise estimates of the cross correlation function by pooling together the seven data sets. In practice, this means that inference about the type of structural disturbances affecting on average the G-7 countries may be more accurate since the mechanism driving output and inflation fluctuations may have been operating in a larger number of instances. For example, one should also a-priori expect fluctuations in the US and Canada to be driven, to a large extent, by similar shocks with the differences previously noted due to small sample sizes. By pooling data together one hopes that this commonality will translate in repeated observations on either the same source or the same propagation mechanism therefore providing a more accurate representation of the forces at work.

The drawbacks of pooling are well understood. Neglecting heterogeneity in the dynamics produces inconsistent estimates of the parameters and biases structural inference, i.e. we get more precise estimates of the possibly wrong source of disturbance. If short term dynamics are the same across countries and the samples are large enough, single countries VARs and the pooled VAR will give identical information on structural sources of output and inflation cycles.

Table 1 shows that in the full sample we identify a real demand, two nominal and one supply disturbance, which are the same types of shocks present in the U.S.. The qualitative similarities obtained for the pooled model and the U.S. are remarkable; not only identified shocks are the same but also their relative importance is similar: nominal and real demand shocks are significant for industrial production variability, while nominal disturbances dominate inflation variability (see table 2).

For the first subsample, we identify three disturbances: two nominal and one real demand shocks. Here nominal disturbances dominate the variability of industrial production, explaining between 74 and $91 \%$ of its variance. They also explain between one-third and two thirds of the variability of inflation and are as important as real demand shocks. For the second subsample, we identify only two shocks, one supply and one nominal, but there are large portions of the variability of pooled industrial production and inflation, which are left unexplained. Hence, it appears that the heterogeneities in the transmission of shocks across countries are very important in this subsample so that averaging produces misleading results.

To summarize, the cross country dynamics following orthogonal VAR innovations are sufficiently homogeneous for the full sample to make estimates of the average dynamics of the three variables in a typical country meaningful and consistent with the information obtained with single country VARs. Overall, the results emphasize once again the important role that demand disturbances, and nominal disturbances, in particular, play in generating real fluctuations in two of the three samples we considered ${ }^{2}$.

\section{The variability of the slope of the term structure}

The literature has documented that movements in the slope of the term can be used to forecast future movements in output and inflation. Moreover, several authors have emphasized that the slope of the term structure carries information about the real side of the economy in the short run

\footnotetext{
${ }^{2}$ We have also examined the typical dynamics obtained by averaging the relevant statistics over the seven countries as suggested by Pesaran and Smith (1995). The results obtained are mixed and the procedure is unable to provide any sharp conclusion about sources of output and inflation cycles.
} 
and about inflation in the long run (see e.g. Plosser and Rouwenshort (1994)). In this section, we would like to know which type of structural disturbances account for the variability of the slope of the term structure, and whether different structural shocks have explanatory power for the slope at different horizons. Our conjecture is that both supply and demand disturbances are responsible for fluctuations in the term structure and that the relative importance of the two types of shocks changes with the time horizon.

Table 3 reports the percentage of variance in the slope of the term structure explained by identified shocks at the 3 and at the 24 months horizons. Four observations can be made. First, demand disturbances account for a sizeable portion of the variability of the slope of the term structure at the short horizon in 6 of the 7 countries ( the exception is Canada). Second, within the demand type of shocks, nominal disturbances appear to dominate. For example, for the full sample they explain between $66 \%$ and $99 \%$ of the slope of the term structure in Japan, UK, Germany, France and Italy. Third, the relative importance of various sources of fluctuations does not significantly change at longer horizons, except for the US and Canada, where supply disturbances loose some of their predictive power in favor of demand shocks, both of real and nominal type. Fourth, demand shocks are totally responsible for the variability of the term structure in the first subsample at both the short and the long horizons and nominal shocks explain the largest proportion in five countries. In the second subsample, demand shocks dominate in four of the seven countries at both short and long horizons. Also in this subsample, nominal disturbances are the most important source of demand variations, even though their relative importance changes relative to the $1973-82$ period in several countries.

These results suggest a unified explanation for fluctuations in real, monetary and financial markets. Also, the conclusion that nominal shocks are important sources of term structure fluctuations agrees with the recent evidence of Evans and Marshall (1998), and is consistent with liquidity theories of monetary policy (see e.g. Christiano, Eichenbaum and Evans (1996)). However, we find almost no evidence that different sources of structural shocks are responsible for term structure variability at different horizons.

\section{Conclusions}

This paper examined the sources of cyclical movements in economic activity and inflation using a novel two-step approach. The proposed procedure is advantageous for several reasons: it uses the joint dynamics of output, inflation and real balances to identify shocks; it clearly separates the statistical issue of obtaining contemporaneously uncorrelated innovations from the one of identifying their informational content and allows to systematically examine the space of identifications. For the cross section of G-7 countries, we find that demand disturbances are important sources of output, inflation and term structure cycles in all countries and in several cases they are dominant source of variability in these three variables. Nominal shocks play an important role for real fluctuations in all countries, but their importance changed somewhat across subsamples. Moreover, for every country and in all subsamples nominal shocks account for the majority of the fluctuations in the slope of the term structure both at short and long horizons.

Some important conclusions can be drawn from our exercise. First, supply disturbances 
seems to play a very small role as source of fluctuations in the post Bretton Wood era so that the emphasis that the RBC literature has put on these shocks seems ill-posed. However, to make the comparison with the existing literature fair, it should be pointed out that the supply disturbances we identify have transitory features while in most of previous exercises (Blanchard and Quah (1989), Gali (1992) and (1999)), identified supply shocks have permanent characteristics. Second, contrary to the conventional wisdom, we find that nominal disturbances play an important role as a source of real fluctuations in all countries. Our results therefore reinforce the claims of Roberts (1993) and Faust (1999), who found that there are identification schemes which give monetary disturbances an important role for output variability in the U.S., and provide empirical support to the recent resurgence of interest in theoretical models where nominal shocks are the engine of the business cycle. Third, although the integration of the real and financial sides of the G-7 economies was well under way especially after 1982, output cycles across countries are still driven by different sources of structural disturbances. This heterogeneity can not be easily rationalized at international level and further studies investigating international linkages across real, monetary and financial markets, along the lines of Canova and De Nicoló (2000), would shed light on these issues. 


\section{References}

[1] Abel, A. and Bernanke, B., 1995, Macroeconomics, Addison and Wesley.

[2] Amhed, S., Ickes, B., Wang, P. and B. Yoo, 1993, "International Business Cycles", American Economic Review, 83, 335-359.

[3] Backus, D. and Kehoe, P., 1992, "International Evidence on the Historical Properties of Business Cycles", American Economic Review, 82, 864-888.

[4] Baxter, M. and Stockman, A., 1989, "Business Cycles and the Exchange Rate Regime: Some International Evidence", Journal of Monetary Economics, 23, 377-400.

[5] Blackburn, K and Ravn, M., 1992, "Business Cycles in the UK: Facts and Fictions", Economica, 59, 383-401.

[6] Blanchard, O., 1989, "A Traditional Interpretation of Macroeconomic Fluctuations", American Economic Review, 79(5), 1146-1164.

[7] Blanchard, O. and Quah, D., 1989, "The Dynamic Effects of Aggregate Demand and Supply Disturbances", American Economic Review, 79, 654-673.

[8] Canova, F. and De Nicoló, G. 2000, "Stock Returns, Term Structure, Output and Inflation: An international Perspective", forthcoming, Macroeconomic Dynamics

[9] Canova, F., and Marrinan, J., 1998, "Source and Propagation of Output Cycles: Common Shocks or Transmission", Journal of International Economics, 46, 133-166.

[10] Canova, F., and Piña, J., 1999, " Monetary Policy Misspecification in VAR models", CEPR Working Paper 2333.

[11] Chada, B. and Prasad, E. 1994, "Are Prices Countercyclical? Evidence from the G-7 countries", Journal of Monetary Economics, 34, 239-254.

[12] Christiano, L. and Eichenbaum, M., 1992, "Current Real Business Cycle Theories and Aggregate Labor Market Fluctuations”, American Economic Review, 82, 430-450.

[13] Christiano, L., Eichenbaum, M. and Evans C., 1996, "The Effect of Monetary Policy Shocks: Some Evidence from the Flow of Funds", Review of Economic and Statistics, LXXVIII, 16-34.

[14] Cooley, T. and Ohanian, L., 1991, "The Cyclical Behavior of Prices", Journal of Monetary Economics, 28, 25-60.

[15] Den Haan, W., 1990, "The Optimal Inflation Path in a Sidrausky-type Model with Uncertainty", Journal of Monetary Economics, 389-409.

[16] Estrella, A. and G. Hardouvelis, 1991, "The Term Structure as Predictor of Real Economic Activity", Journal of Finance, XLVI, 555-576. 
[17] Evans, C. and Marshall, D., 1998, The economic determinants of the term structure of nominal interest rates, Carnegie and Rochester Conference Series, 49, 51-111.

[18] Farmer, R., 1997, "Money in a Real Business Cycle Model", Journal of Money, Banking and Credit, $29,568-611$.

[19] Faust, J., 1998, "On the Robustness of the Identified VAR conclusions about money", Carnegie Rochester Conference Series on Public Policy, 49, 207-244.

[20] Faust, J. and Leeper, E., 1997, "When do Long Run Identifying Restrictions Give Reliable Results", Journal of Business and Economic Statistics, 15, 345-353.

[21] Fiorito, R. and Kollintzas, T., 1994, "Business Cycles In the G-7", European Economic Review, 38, 235-269.

[22] Gali, J., 1992, "Does the IS-LM model Fit US Postwar Data?", Quarterly Journal of Economics, CVII, 708-738.

[23] Gali, J., 1999, "Technology, Employment and the Business Cycle: Do Technology Shocks Explain Aggregate Fluctuations?" American Economic Review, 89, 249-271.

[24] Gavin, B. and Kydland, F., 1999, " Endogenous Money Supply and the Business Cycle”, Review of Economic Dynamics, 2, 347-369.

[25] Gregory, A., Head, A. and Raynauld, J., 1997, "Measuring World Business Cycles", International Economic Review, 38, 677-702.

[26] King, R., C. Plosser, J. Stock and M. Watson, 1991, "Stochastic Trends and Economic Fluctuations", American Economic Review, 81(4), 819-840.

[27] Kim, S., 1999, "Do monetary policy shocks matter in the G-7 countries? Using common identifying assumptions about monetary policy across countries", Journal of International Economics, 48, 387412.

[28] Leeper, E, Sims, C. and Zha, T., 1996, 'What does monetary policy do?"', Brookings Paper on Economic Activity, 1, 1-75.

[29] Lucas, R, 1972, "Expectations and the Neutrality of Money", Journal of Economic Theory, 4, 103124.

[30] Judd, J. and Trehan, B., 1995," The Cyclical Behavior of Prices: Interpreting the Evidence", Journal of Money, Banking and Credit, 27, 789-797.

[31] Mankiw, G. ,1985, "Small Menu Costs and Large Business Cycles: A Macroeconomic Model of Monopoly", Quarterly Journal of Economics, 100, 529-538.

[32] Pesaran, H. and Smith, R., 1995, "Estimating Long Run Relationships from Dynamic Heterogeneous Panels", Journal of Econometrics, 68, 79-113. 
[33] Plosser, C. and G. Rouwenhorst, 1994, "International Term Structure and Real Economic Growth", Journal of Monetary Economics, 33, 133-155.

[34] Press, A., 1985, Numerical Recipes: The Art of Scientific Computing, Cambridge: Cambridge University Press.

[35] Roberts, John M., 1993, "The Sources of Business Cycles: A Monetarist Interpretation", International Economic Review, vol. 34, n.4, 923-934.

[36] Sims, C,. 1980, "Comparison of Interwar and Postwar Business Cycles: Monetarism Reconsidered", American Economic Review, Paper and Proceedings, 70, 250-257.

[37] Stock, J. and M. Watson, 1989, "New Indexed of Coincident and Leading Economic Indicators", NBER Macroeconomic Annual 1989, 4, 351-393.

[38] Ulhig, H., 1999, "What are the Effects of Monetary Policy: Results from an Agnostic Identification Approach", Tilburg University, CentER working paper 9928. 
Table 1: Identification

\begin{tabular}{|c|c|c|c|c|c|c|}
\hline Country & Rotation & $\theta$ & Shock 1 & Shock 2 & Shock 3 & Shock 4 \\
\hline \multicolumn{7}{|c|}{ Sample 1973:1-1995:7 } \\
\hline US & 8 & 0.94 & Nominal & Supply & Real Demand & Nominal \\
\hline GERMANY & 5 & 0.47 & Nominal & Real Demand & Nominal & \\
\hline JAPAN & 8 & 1.53 & Nominal & Nominal & & Nominal \\
\hline UK & 1 & 0.31 & Real Demand & Nominal & Nominal & Nominal \\
\hline FRANCE & 6 & 1.09 & Real Demand & Nominal & Supply & Real Demand \\
\hline ITALY & 1 & 0.31 & Supply & Nominal & Nominal & Nominal \\
\hline CANADA & 1 & 0.62 & Nominal & Supply & Supply & Supply \\
\hline POOLED & 7 & 0.47 & Real Demand & Nominal & Nominal & Supply \\
\hline \multicolumn{7}{|c|}{ Sample 1973:1-1982:10 } \\
\hline US & 4 & 0.62 & Nominal & Nominal & Nominal & Real Demand \\
\hline GERMANY & 9 & 0.94 & & & Nominal & Real Demand \\
\hline JAPAN & 1 & 0.00 & Real Demand & Nominal & Nominal & Nominal \\
\hline UK & 3 & 0.47 & Real Demand & Nominal & & Nominal \\
\hline FRANCE & 3 & 0.00 & Real Demand & Nominal & Nominal & \\
\hline ITALY & 1 & 0.47 & Supply & Nominal & Nominal & Nominal \\
\hline CANADA & 4 & 1.09 & Real Demand & & Nominal & Nominal \\
\hline POOLED & 1 & 0.62 & Nominal & Real Demand & Nominal & \\
\hline \multicolumn{7}{|c|}{ Sample 1982:11-1995:7 } \\
\hline US & 2 & 0.31 & Nominal & Real Demand & Nominal & Nominal \\
\hline GERMANY & 1 & 1.25 & Supply & Nominal & & Nominal \\
\hline JAPAN & 5 & 1.09 & & Nominal & Real Demand & Real Demand \\
\hline UK & 4 & 1.25 & & Real Demand & Nominal & \\
\hline FRANCE & 2 & 0.62 & Real Demand & Supply & Nominal & Nominal \\
\hline ITALY & 7 & 0.31 & Nominal & Supply & Supply & Supply \\
\hline $\mathrm{CAN}$ & 7 & 1.41 & Supply & Nominal & Supply & \\
\hline POOLED & 7 & 0.94 & & & Supply & Nominal \\
\hline
\end{tabular}

Notes: In the rotation column, 1 indicates that the first two elements of the covariance matrix are rotated; 2 indicates that elements one and three of the covariance matrix are rotated; 3 indicates that elements one and four of the covariance matrix are rotated; 4 indicates that elements two and three of the covariance matrix are rotated; 5 indicates that elements two and four of the covariance matrix are rotated; 6 indicates that elements three and four of the covariance matrix are rotated; 7 indicates that elements one and two, and three and four of the covariance matrix are contemporaneously rotated; 8 indicates that elements one and three, and two and four of the covariance matrix are contemporaneously rotated; 9 indicates that elements one and four, and two and three of the covariance matrix are contemporaneously rotated. $\theta$ measures the angle of rotation. 
Table 2

Percentage of the 24 month Forecast Error Variance of Industrial Production and Inflation Explained by Structural Innovations

\begin{tabular}{l|ccc|ccc}
\hline \hline $\begin{array}{l}\text { Structural } \\
\text { Innovations }\end{array}$ & NOMINAL & $\begin{array}{c}\text { REAL } \\
\text { DEM AND }\end{array}$ & SUPPLY & NOMINAL & $\begin{array}{c}\text { REAL } \\
\text { DEMAND }\end{array}$ & SUPPLY \\
\hline \multicolumn{5}{|c}{ Variance of Industrial } \\
Production
\end{tabular}

Notes: The forecast error variance is computed using a 4 variable VAR model. The table shows the $68 \%$ error band for the 24 month forecast error variance in the variable explained by sources of structural innovations. Bands are computed using Monte Carlo replications. 
Table 3

Percentage of the Forecast Error Variance of the

Slope of the Term Structure Explained by Structural Innovations

\begin{tabular}{|c|c|c|c|c|c|c|}
\hline $\begin{array}{l}\text { Structural } \\
\text { Innovations }\end{array}$ & NOMINAL & $\begin{array}{l}\text { REAI } \\
\text { EMAI }\end{array}$ & SUPPLY & \multicolumn{3}{|c|}{ DEMAND } \\
\hline & \multicolumn{3}{|c|}{3 month horizon } & \multicolumn{3}{|c|}{24 month horizon } \\
\hline & \multicolumn{6}{|c|}{ Sample 1973:1-1995:7 } \\
\hline POOLED & $1-67$ & $2-7$ & $28-94$ & $14-55$ & $10-25$ & $26-68$ \\
\hline USA & $25-58$ & $0-22$ & $38-56$ & $25-57$ & $13-37$ & $24-42$ \\
\hline CANADA & $0-3$ & & $96-99$ & $18-34$ & & $66-82$ \\
\hline JAPAN & $98-99$ & & & $73-91$ & & \\
\hline UK & $95-99$ & $0-5$ & & $77-95$ & $5-23$ & \\
\hline GERMANY & $98-99$ & $0-2$ & & $26-54$ & $0-2$ & \\
\hline FRANCE & $66-84$ & 14- 32 & $0-1$ & $49-72$ & $14-33$ & $4-23$ \\
\hline \multirow[t]{2}{*}{ ITALY } & $98-99$ & & $0-2$ & $95-99$ & & $0-4$ \\
\hline & \multicolumn{6}{|c|}{ Sample 1973:1-1982:10 } \\
\hline POOLED & $86-97$ & $1-12$ & & $76-87$ & $2-11$ & \\
\hline USA & $69-96$ & $4-31$ & & $58-95$ & $4-42$ & \\
\hline CANADA & $89-98$ & $0-4$ & & $55-87$ & $6-37$ & \\
\hline JAPAN & $97-99$ & $0-3$ & & $78-94$ & $6-22$ & \\
\hline UK & $93-98$ & $0-4$ & & $61-83$ & $2-17$ & \\
\hline GERMANY & $19-46$ & $0-12$ & & $10-26$ & $3-50$ & \\
\hline FRANCE & $3-11$ & $5-17$ & & $13-39$ & $7-26$ & \\
\hline \multirow[t]{2}{*}{ ITALY } & $91-99$ & & $0-8$ & $83-99$ & & $1-16$ \\
\hline & \multicolumn{6}{|c|}{ Sample 1982:11-1995:7 } \\
\hline POOLED & $3-69$ & & $27-93$ & $18-45$ & & $35-61$ \\
\hline USA & $97-99$ & $0-3$ & & $90-99$ & $1-10$ & \\
\hline CANADA & $0-2$ & & $3-7$ & $27-52$ & & 4-13 \\
\hline JAPAN & $35-63$ & $29-56$ & & $21-47$ & $22-43$ & \\
\hline UK & $91-96$ & $0-5$ & & $4-14$ & $5-23$ & \\
\hline GERMANY & $20-39$ & & $59-78$ & $34-56$ & & $18-55$ \\
\hline FRANCE & $93-99$ & $0-5$ & $0-2$ & $77-96$ & $0-13$ & $0-14$ \\
\hline ITALY & $0-3$ & & $97-99$ & $0-7$ & & $93-99$ \\
\hline
\end{tabular}

Notes: The forecast error variance is computes using a 4 variable VAR model. The table shows the $68 \%$ error band for the forecast error variance in the variable explained by sources of structural innovations. Bands are computed using Monte Carlo replications. 
Figure 1

Conditional Cross-Correlations in a Shopping Time Model
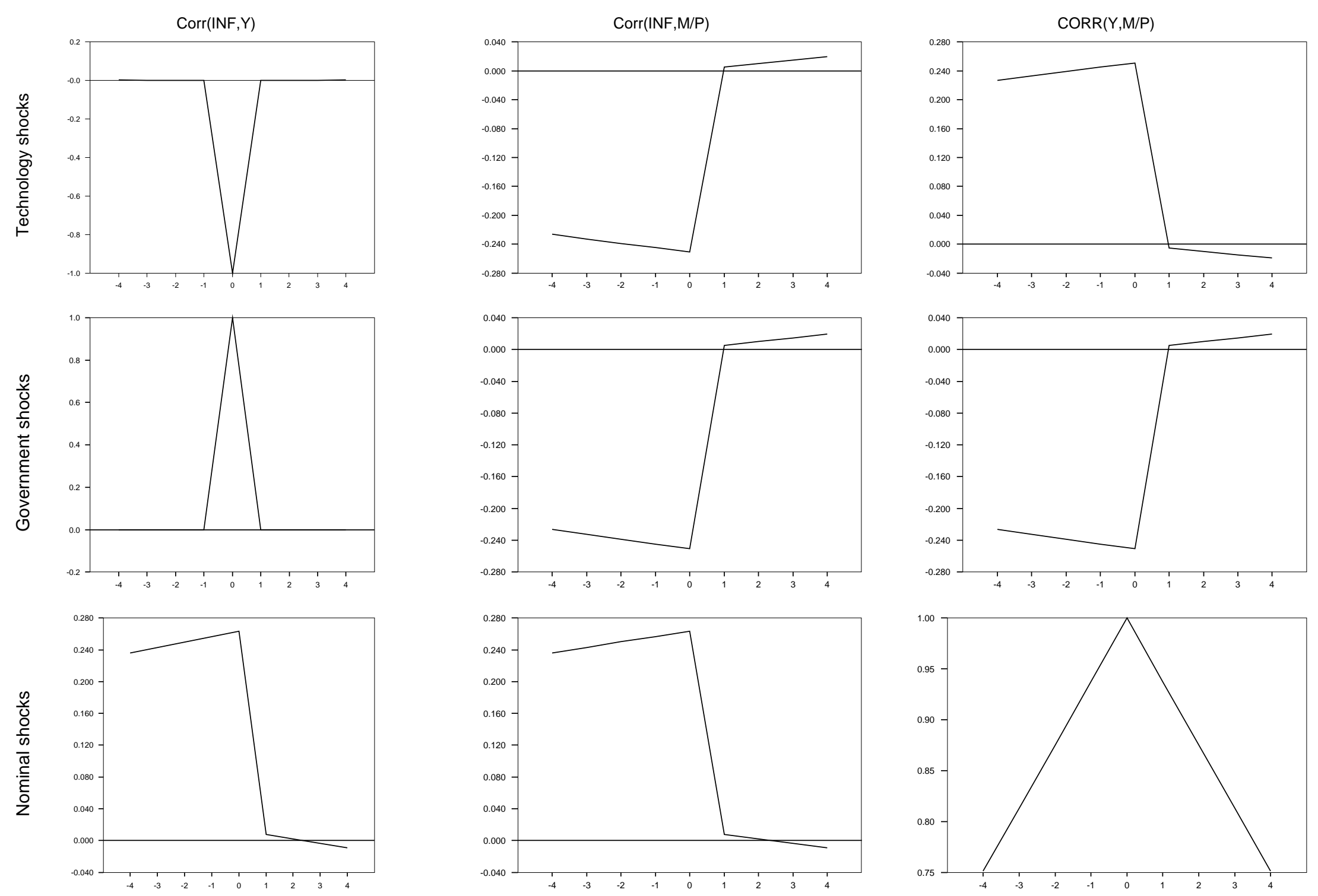


\section{Figure 2: US, Cross Correlations}

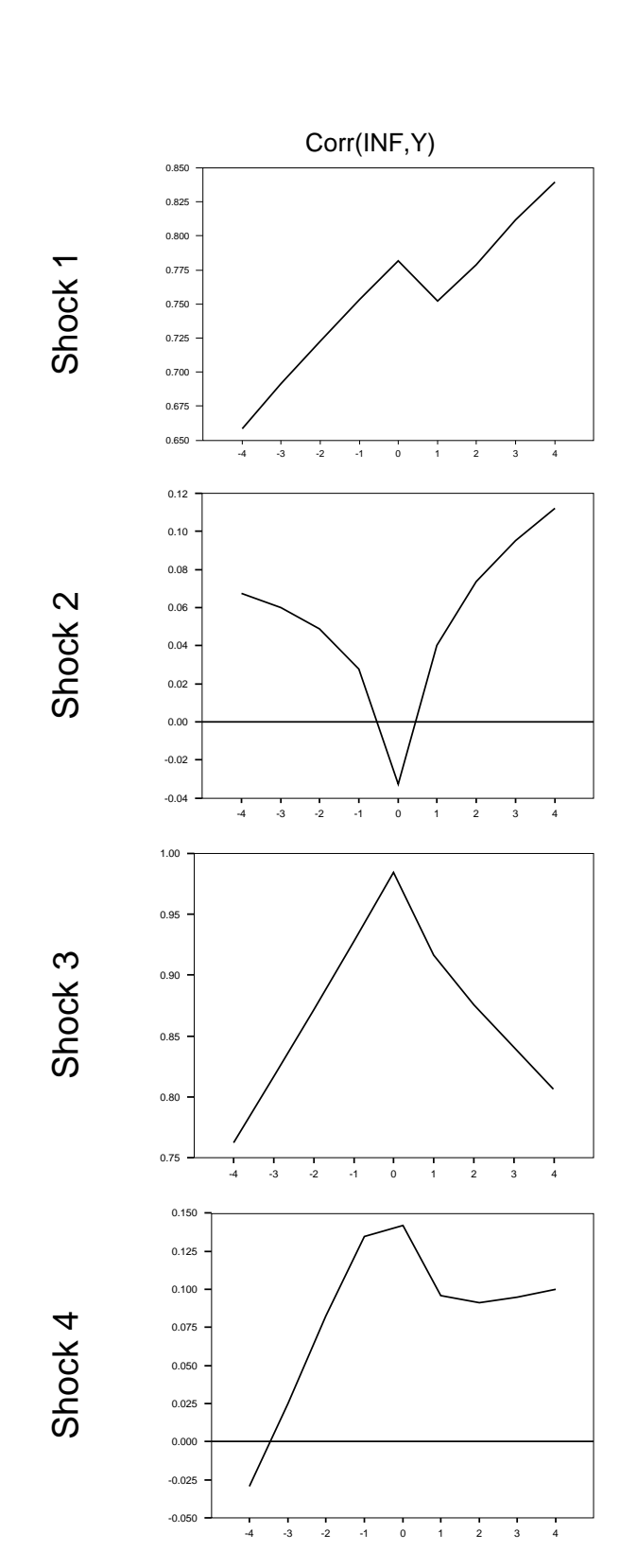

1973:01-1995:07
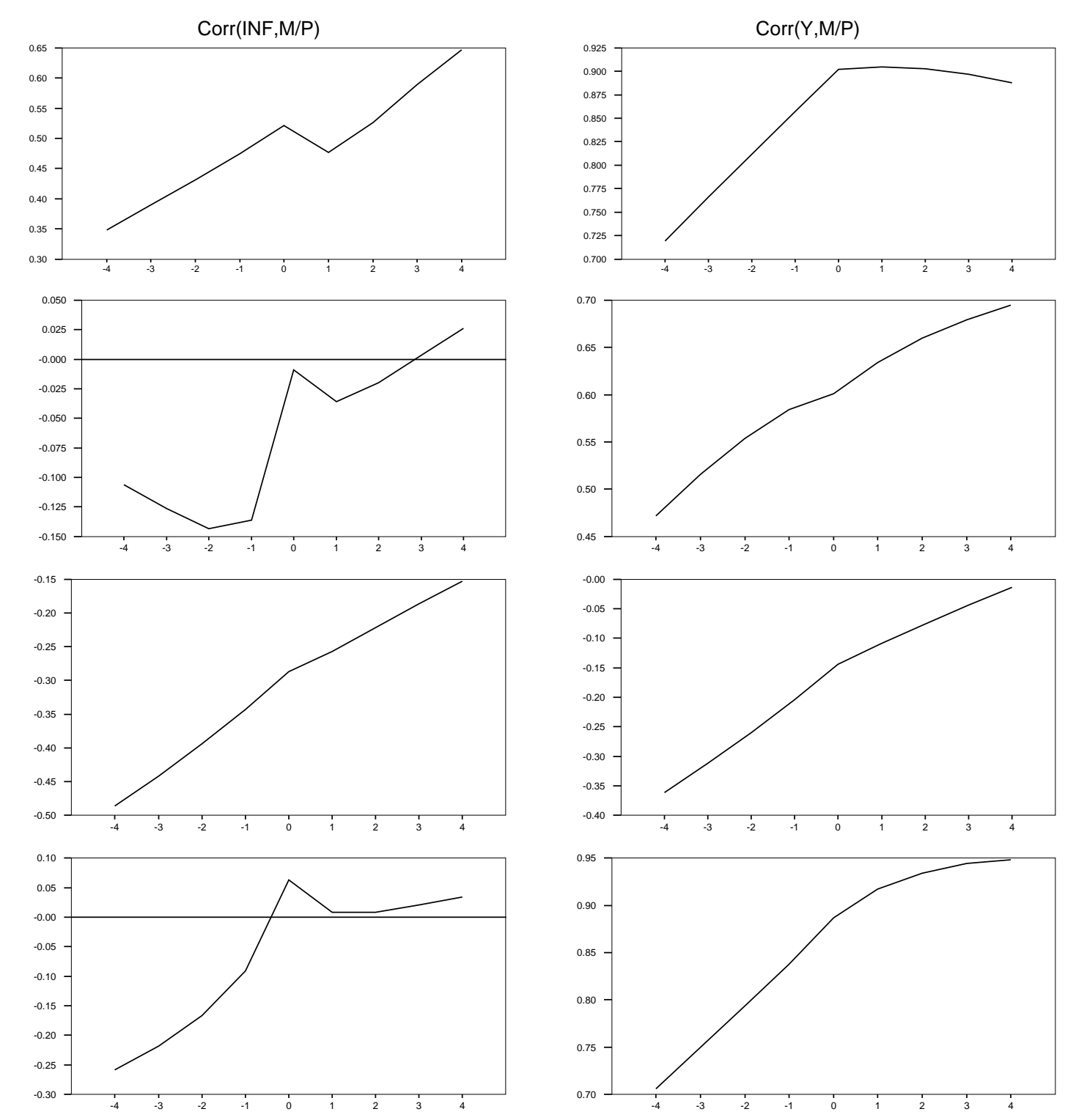

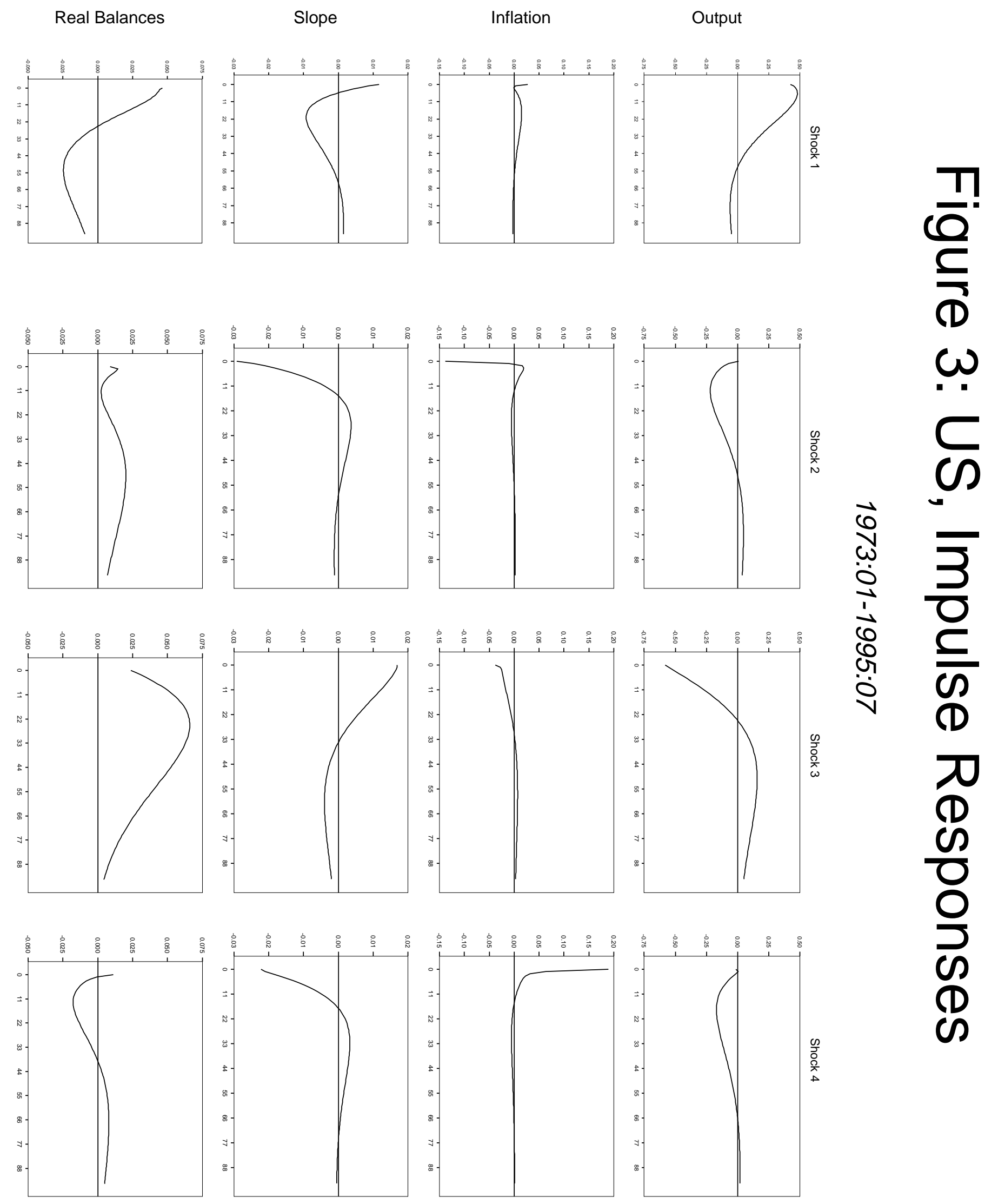


\section{Figure 4: Responses to Nominal Shocks}

1973.1-1995.07
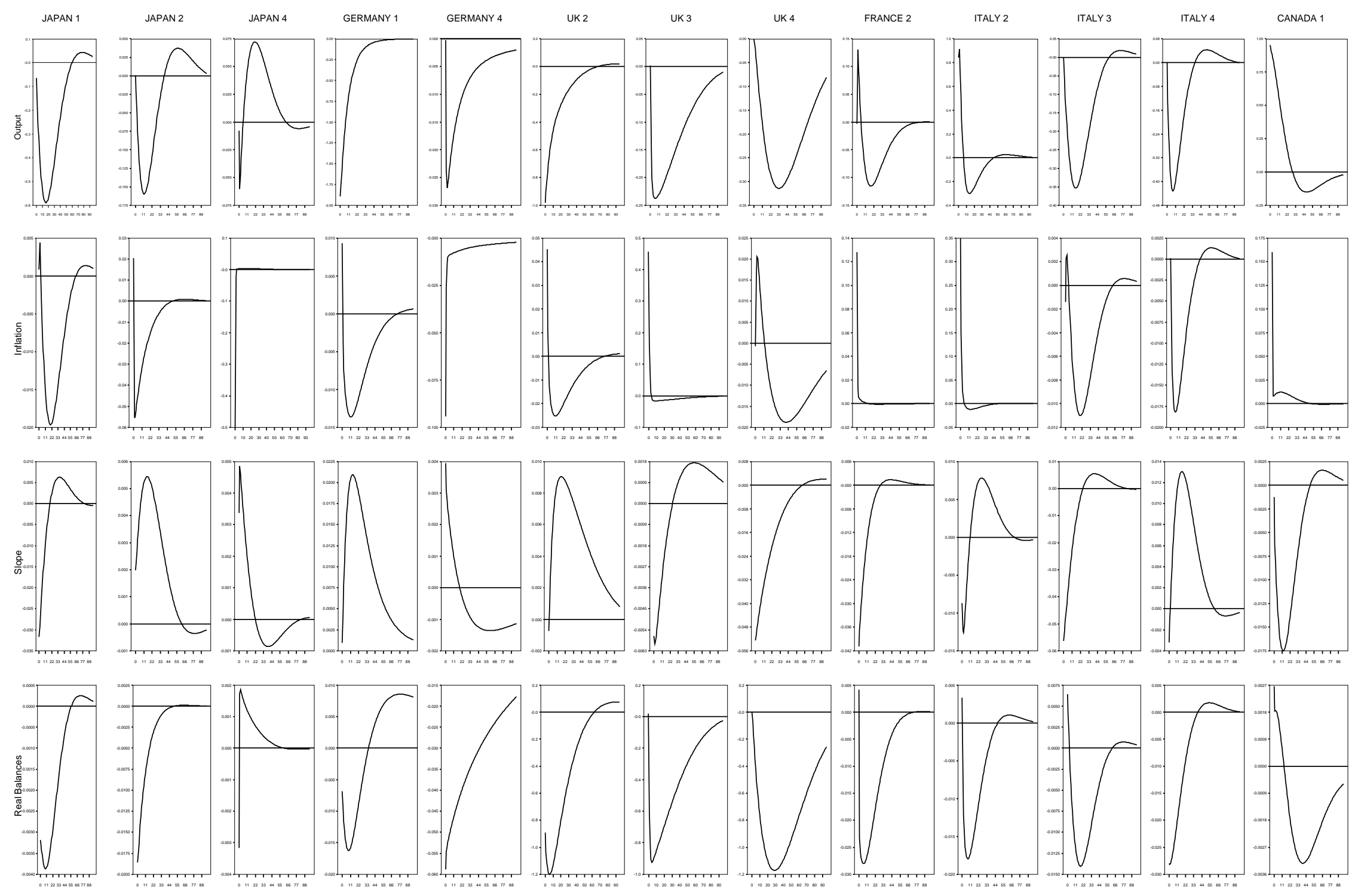


\section{Figure 5: Responses to Real Demand Shocks}

1973.1-1995.07
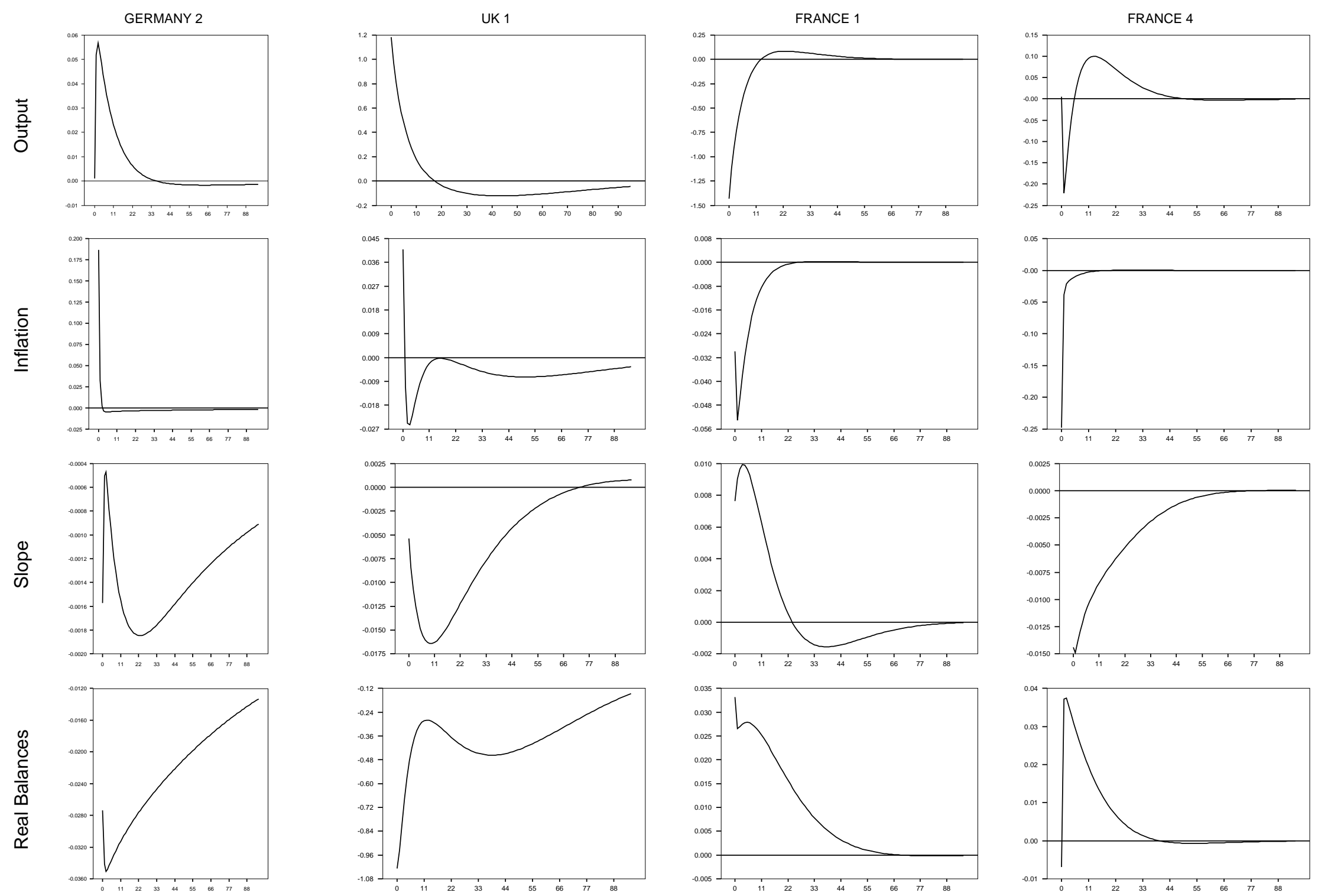


\section{Figure 6: Responses to Supply Shocks}

1973.1-1995.07
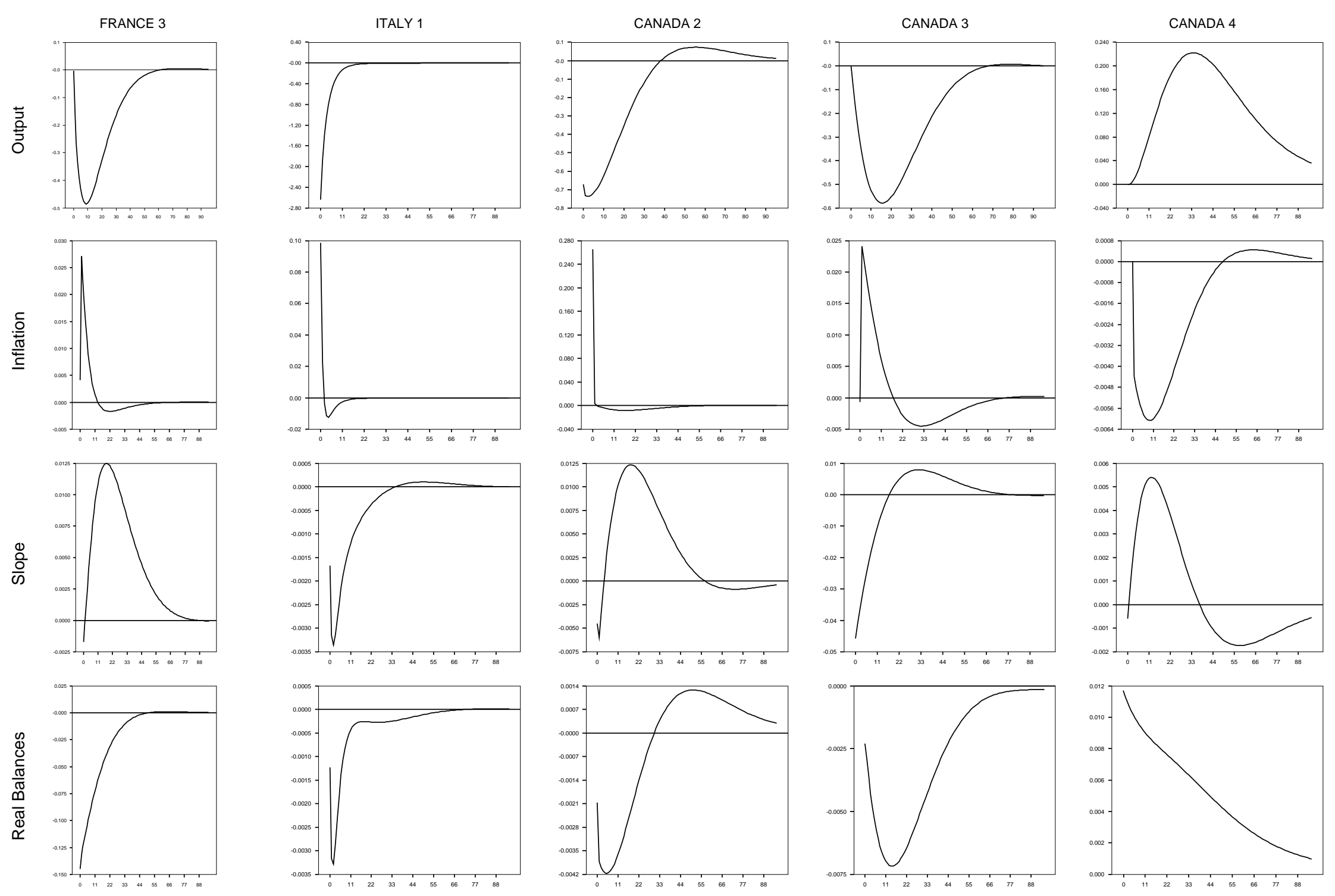